\title{
The Future Role of Vocational Education Teachers in the Professional Learning Communities in Public Schools from the Perspective of Principals and Academic Supervisors in Jordan
}

\author{
Sameer Aowad Kassab Shdaifat ${ }^{1}$ \& Al-Huson ${ }^{2}$ \\ ${ }^{1}$ Al- Balqa' Applied University (BAU) \\ ${ }^{2}$ Head of the vocational education department Assistant professor \\ Correspondence: Sameer Aowad Kassab Shdaifat, Al- Balqa' Applied University (BAU), Jordan.
}

Received: July 9, 2020

doi:10.5430/ijhe.v9n5p322
Accepted: August 5, 2020

Online Published: August 13, 2020

URL: https://doi.org/10.5430/ijhe.v9n5p322

\begin{abstract}
The present study aims to explore the future role of vocational education teachers in the professional learning communities in public schools from the perspective of principals and academic supervisors in Jordan. The sample consists from 91 principals and academic supervisors. Those principals and academic supervisors were selected from the public schools that are under the supervision of Bani Obeid Directorate of Education in Irbid, Jordan. The present study was conducted during the academic year (2019/2020). A descriptive approach is adopted by the researcher. The researcher developed a questionnaire that consists from 25 items. He measured the validity and reliability of the questionnaire. It was found that principals and academic supervisors have positive attitudes towards the future role of vocational education teachers in the professional learning communities in public schools. It was found that there isn't any significant difference between the respondents' attitudes which can be attributed to their experience or academic qualification. The researcher recommends creating vocational training departments in public schools
\end{abstract}

Keywords: future role, teachers, vocational education, principals, academic supervisors, professional learning communities, jordan, public schools

\section{Introduction}

Due to information explosion, school today isn't the only source of knowledge. Therefore, in order for any school to excel and survive, its staff must keep learning in an ongoing manner. Therefore, the mission of schools today isn't represented in teaching students only. In fact, it also includes delivering knowledge to leaders, teachers, administrators, students, parents and other members of the society. In other words, schools have become learning organizations.

Moilanen (2011) suggests that the term (learning organization) refers to the organization that is managed in an organized systematic manner and seek providing much attention to learning. The management of the learning organization considers learning as something very essential that adds value to it. The vision, goals and daily operations of the learning organization address learning-related issues. The management of the learning organizations seek eliminating the barriers hindering employees from learning. They seek facilitating the learning process for employees (Moilanen, 2011).

In order for any school to become a learning organization, it must provide much attention to the learning process. It must develop the staff in an ongoing manner. It must improve the capabilities of the staff in an ongoing manner. It must improve the thinking skills of its staff. It must promote collaboration among the staff in order to carry out tasks and activities efficiently and meet the intended goals. In order for any school to become a learning organization, it must have wise leaders who address learning-related issues through the school goals, and strategies. It must have wise leaders who integrate learning in the daily activities of the school (Abu Al-Nour, 2010).

It has been suggested that the capability of an organization to make reforms is affected by the extent of attention it grants for establishing a (professional learning community) (or community of practices). A professional learning community refers to a group of teachers who engage in the leadership activities, and decision making process. Those teachers have common goals and collaborate and cooperate with each other. They handle a shared responsibility for their works (Mohammad, 2019). 
Based on the aforementioned information, establishing a professional learning community in schools contributes to achieving professional development in schools. It contributes to making reforms and developing schools. It has been proved that the obligatory school reforms determined by officials can't achieve the intended goals. That is because the officials who determine such reforms don't take into consideration the differences between schools in terms of financial and human resources and organizational structures. It's because such officials don't take into consideration how ready each school is to make those reforms. It's because such officials don't take into consideration how motivated and willing the staff of each school to make these reforms. Overlooking these things shall negatively affect the effectiveness of those reforms in meeting the intended goals (Hasanian, 2008).

Al-Hussaini and Al-Zghool (2009) suggest that there is need to adopt a new reformative approach by school managements. It is because the schools adopting conventional management approach have been showing failure in turning themselves into learning organizations. Al-Hussaini and Al-Zghool (2009) suggest that reforms must be determined by the school management itself. That is because the reforms that are determined by officials are ineffective in meeting the intended goals (Al-Hussaini and Al-Zghool, 2009).

A professional learning community aims at developing schools and making reforms that are planned by the leaders of the school itself. In the professional learning community, the reforms are based on the vision and mission of the school itself. In this community, the leaders of the school take into consideration the financial and human resources of the school. They seek collaborating with each other. In this community, students, teachers, administrators, and the members of the society cooperate with each other (Morrissey, 2014)

Dover and Eker (2008) suggest that the professional learning community in a school provides excellent outcomes. In this community, teachers, principals, and parents collaborate with each other in order to make effective decisions. They also cooperate with each other when carrying out processes. They exchange views and expertise with each other. Thus, creating a professional learning community shall contribute to developing the learning outcomes of students. However, it isn't a simple process. In fact, it requires making major changes to the organizational structure of school.

When the school community turns into a learning community, the school staff shall become open to several global and local learning communities. Having a learning community at the school shall provide the school staff with knowledge about several models of learning communities. It enables the school staff to benefit from the expertise of others. It expands the knowledge of the school staff. It enables the teachers and students to communicate with their colleagues in other schools and exchange expertise with them. It improves the learning environment of the school (Fuller, 2015).

The professional learning communities seek making reforms to the education system. In fact, such communities made dramatic reforms to education in the United States, United Kingdom, Canada, Australia, France, Germany, China, and etc. Turning the school community into a professional learning community requires having leaders who develop the employees' leadership skills. It requires having leaders who let the employees engage in the decision making process. It requires having leaders who let the employees engage in the process of allocating the leadership activities to employees. It requires having leaders who encourage employees to exchange expertise with each other. It requires having leaders who promote team work (Melton, 2010). Earley and Weindling (2004) suggest that turning the school community into a professional learning community requires ensuring that the students and teachers are learning effectively. They add that turning the school community into such community requires adopting a leadership style that facilitates the learning process for students, teachers and administrators (Earley and Weindling, 2004).

The professional learning community provides teachers with opportunities to cooperate in the learning and planning processes. Such cooperation enables teachers to track the students' progress. It enables teachers to identify the students who are in need for more time to meet the learning goals. Teachers can identify those students through using collective assessment methods. It should be noted that teachers play a significant role in turning the school community into a professional learning community. For instance, teachers can create a convenient learning environment in the classroom. They can promote respect for criticism in the classroom. They can promote acceptance for others' opinions in the classroom. They can encourage learners to find creative solutions for solving their problems (Mohammad, 2009).

The vocational education (VE) teachers have more knowledge than other teachers. They are also provided with theoretical knowledge while learning. Several researchers aimed to identify the way in which the VE teachers should practice their profession during the $21^{\text {st }}$ century in order to turn the school community into a professional learning community. According to Hussein et al. (2018), VE teachers should use conventional and alternative assessment 
strategies for assessing students' development in all areas. They should encourage students to learn in an ongoing manner. They should use effective communication methods to communicate effectively with students. They should implement the continuous improvement strategy. That shall contribute to delivering education of high quality. VE teachers should develop students' critical thinking skills (Hussein et al., 2018).

VE teachers play a significant role in the teaching-learning process. They should deliver vocational education through letting students adopt investigative and exploratory approaches and practice handworks. They should deliver vocational education through letting students work in the VE workshop, shops, factories, and the school yard. They must teach students the way they ought to think and learn rather than the way of memorizing the information included in the curriculum without understanding it (Atteyeh, 2010).

\section{Statement of the Problem}

There are several modern trends that aim at turning the school community into a professional learning community. Educational leaders aim at establishing such a community in order to develop the school. Establishing this community requires having collaboration between the principal, and employees. It should be noted that many governments today seek turning school communities into professional learning communities. In order to do that, these governments today seek providing staff at schools with attention and professional development opportunities. That is because school staff play a significant role in promoting a culture of cooperation among learners (Tawfiq, 2017).

Teachers are always in need for developing themselves professionally. That is because teachers are always in need for expanding their knowledge about modern trends in the educational and instructional technology fields. It's because teachers are always in need for acquiring new skills. It's because knowledge has been significantly developing. Therefore, the teaching profession is associated with ongoing professional development. That is suggested by Wong (2010) and Mik (2013). The latter researchers suggest that having professional learning communities in schools shall enable teachers to develop themselves professionally. They add that having such communities in schools contribute to the promotion of collaboration and cooperation among teachers. Raymond (2016) suggests that a professional learning community is established when the teachers cooperate and collaborate effectively with each other. Mursi and Al-Qusairi (2018) suggest that having a professional learning community in the school plays a significant role in improving the performance of teachers in vocational secondary schools in Egypt.

In the light of the aforementioned information, establishing a professional learning community in school is affected by the degree to which the teachers recognize their future roles. Through reviewing the relevant literature, it can be noticed that there aren't many studies that shed a light on the role and tasks of vocational education teachers in the professional learning communities in schools. Hence, the researcher of the present study aims to explore the future role of vocational education teachers in the professional learning communities in public schools from the perspective of principals and academic supervisors in Jordan.

\section{The Study's Questions}

The researcher of the present study aims to answer the following questions:

Q.1. What is the future role of vocational education teachers in the professional learning communities in public schools from the perspective of principals and academic supervisors in Jordan in the schools that are under the supervision of Bani Obeid Directorate of Education in Irbid?

Q.2. Is there any statistically significant differences between the respondents' attitudes which can be attributed to academic qualification or experience?

\section{The Study's Significance}

The present study is significant due to the following reasons:

-The present study sheds a light on an important trend in education (i.e. the professional learning community). Several studies proved that the creating professional learning communities in schools contribute to achieving development. Thus, the results of this study contribute to improving schools and making reforms to them.

-The present study provides decision makers in schools and officials with knowledge about the meaning and principles of professional learning communities. 
-The present study promotes awareness among school leaders, teachers and administrators about the significance of cooperation. It contributes to promoting awareness among school leaders and staff about the significance of planning, assessing and implementing projects that aim at achieving development and making reforms.

\section{Definition of Terms}

The definitions of the study's terms:

-Future role (the theoretical definition): It refers to the expected behaviours of one within a specific group. One's behaviour is determined based on his/her expectations and what others expects from him/her to do. These expectations are determined by the way one and others perceive his/her duties and rights (Hussein et al., 2018).

-Future role (the operational definition): It refers to the attitudes of the sampled principals and academic supervisors towards the future role of vocational education teachers in the professional learning communities in public schools in Jordan. These attitudes were explored through the study's questionnaire.

-Vocational education: According to the Ministry of Education, the vocational education course is a course that sheds a light on various fields. Such fields include: the agricultural, industrial, business, occupational safety and health and home economics. This course aims at providing learners with daily life skills. It enables learners to identify their interests in an early age. It facilitate the process of choosing the future career (cited in Al-Jarrah (2012).

-The professional learning community (the theoretical definition): According to Hord (1997), the professional learning community refers to the school community in which the teachers and administrators collaborate in an ongoing manner with each other to keep learning. Such collaboration enables the teachers and administrators to develop themselves professionally. It has positive impacts on learners. The professional learning community may be called the (community of ongoing research and development).

-The professional learning community (the operational definition): It refers to the school community in which the VE teachers interact with each other and people in the surrounding environment. Such interaction may be face-to-face or digital interaction. In this community, the VE teachers collaborate with each other and have a common vision. In this community, the VE teachers seek learning from each other. They also seek learning from teachers in other communities. They seek establishing relationships with each other in order to cooperate in educational area. They have much creativity and seek solving problems. They have excellent thinking capabilities. They are highly motivated to keep learning in an ongoing manner. They are open to others

\section{The Study's Limits}

The study's limits are listed below:

-Human limits: The researcher selected a sample that consists from several principals and academic supervisors in public schools.

-Temporal limits: The present study was conducted during the first semester of the academic year (2018/2019).

-Spatial limits: The present study was conducted in the public schools that are under the supervision of Bani Obeid Directorate of Education in Irbid.

-Thematic limits: The present study aims to explore the future role of vocational education teachers in the professional learning communities in public schools from the perspective of principals and academic supervisors in Jordan.

\section{The Study's Limitations}

The results of the present study can't be generalized. That is because these results are limited to the study's instrument and its validity and reliability

\section{Theoretical Framework}

The professional learning community refers to the community in which the employees collaborate with each other in order to achieve the same goal. In this community, the employees cooperate with each other to identify and improve the strengths of each one of them. They respect having diversity in terms of opinions. They utilize the available learning opportunities. They seek promoting a culture of cooperation. They seek developing the capabilities of each other. They seek producing knowledge and exchanging it (Abed Al-Mu'ti, 2012). According to Al-Salem (2005), the professional learning community in school involves students, teachers, administrators and other employees who have a sense of belonging to this community. The members of this community seek cooperating with each other in order 
to make improvements in an ongoing manner. Such improvements are made to meet the needs of learners. They are made through developing a common vision and adopting the same approach (Abed Al-Mu'ti, 2012).

Al-Sagh'eer (2009) suggests that the expression (professional learning community) refers to a group of people who have similar interests, problems and responses towards specific topics. The members of the professional learning community seek expanding their knowledge and expertise through having ongoing interaction with each other and people in other learning communities (Al-Sagh'eer, 2009). The term (learning organization) emerged during the late 1980s in the United States of America (Christopher, 2008). Christopher (2008) defines the (learning organization) as the organization in which the capabilities of individuals improve in an ongoing manner in order to achieve the intended goals. In the learning organization, modern thinking patterns are adopted and group ambitions can be achieved. In the learning organization, individuals keep learning in ongoi ng manner (Christopher, 2008). The term (learning organization) became widely acknowledged because it is used by many educators and in many news articles and research articles.

The term (learning community) is a modern concept. Thus, there isn't a specific definition for this term. In fact, the meaning of the term (learning community) differs from one context to another. In general, the term (learning community) refers to the community in which a group of employees work, cooperate, guide and collaborate together. In this community, the employees seek criticizing the practices of each other in a constructive manner. In this community, the employees seek understanding each other and achieving growth and improvement in an ongoing manner (Al-Mahmadain and Mousa, 2017).

Al-Nabawi (2007) suggests that that professional learning community in school is the community in which the leaders seek setting the required foundations for facilitating the learning process of employees. He adds that the employees in this community seek adapting themselves with the changes. Abu Al-Nour (2010) suggests that it is very important to establish a professional learning communities in schools. He adds that establishing such communities requires developing the organizational structure and promoting innovation. He adds that establishing such communities requires developing the teachers professionally and enjoying a high organizational resilience level (Abu Al-Nour, 2010).

According to Tawfiq (2017), such communities are based on having a common vision. In such communities, much attention is given to the relationships between employees. The leaders seek developing the human resources in an ongoing manner in order to achieve ongoing development. If the school leaders want to turn the school community into a professional learning community, they must ensure that students and teachers are learning effectively. They must also adopt a leadership style that turns all the concerned individuals (including students, teachers and administrators) into learners. They must also provide much attention to the opinions of each individual. They must engage all the concerned individuals in activities and the decision making process. To establish a professional learning community, each individual must handle the responsibility of his/her own learning process. There must be a culture of cooperation and support (Tawfiq, 2017).

The members of the learning community facilitate the learning process for each other. They seek making changes in an ongoing manner. They seek learning through acquiring experiences, observing others and exchanging expertise with each other. They also seek learning through exchanging expertise with people in other learning communities. They provide much attention to the learning process. All the members of the learning community are provided with learning opportunities regardless of their job level. In fact, the learning process is an integral part of the workplace culture in the learning community.

Raymond (2016) suggests that all schools must turn their communities into professional learning communities. In such communities, the staff keep learning in an ongoing manner. They seek improving the outcomes. Creating a professional learning community requires having a common vision. It requires having much cooperation between the employees. It requires having effective leaders and showing much support to the employees. It requires having convenient work conditions. The professional learning community in school attracts professionals and promoting collaboration in the aim of acquiring new knowledge. Creating a professional learning community requires: having trust between the employees. It requires having much knowledge about the requirements that must be met for developing the schools. It requires having effective leadership that encourages employees to observe in the aim of acquiring knowledge. It requires having effective leadership that allows employees to make adjustments.

Thus, creating a professional learning community requires having mutual trust among employees of all organizational levels. It requires having employees who are aware of the requirements that must be met for achieving development. It requires having leaders who are willing to make changes to the working method. Those leaders must be capable to think effectively. They must be adopting an observational learning approach. The professional learning communities 
differ from other types of communities. According to Mohammad (2019) and Tawfiq (2017), the members of this community can anticipate future problems. They seek acquiring knowledge about the external environment. They seek making improvements in an ongoing manner. In this community, the leaders seek rewarding the ones who make innovations and make initiatives. They make sure that each job has a job description. They encourage the staff to explore things, make initiatives and exchange information with each other (Mohammad, 2019, Tawfiq, 2017).

The members of this community can predict the problems that might face the school in the future. They seek gaining information about the external environment. They seek seizing the available opportunities and handling risks. They seek cooperating and provide attention to the culture of dialogue. They seek learning and teaching each other. They seek utilizing the data collected through assessment in order to track progress. The school that has a professional learning community enjoys a high organizational flexibility level. It has excellent capabilities to adjust itself with the changes. That enables the school to make improvements in an ongoing manner (Haidar and Al-Mosailihi, 2006).

The learning community is the community that is capable to adjust itself and adjust the internal structure of the organization. The members of this community seek cooperating with each and have dialogues with each other. They provide much attention to team work. DuFour and Eaker (2008) suggest that the most effective strategy for making improvements in schools is represented in improving the capabilities of the school staff and creating a professional learning community. Under this strategy, each employee shall practice leadership. Under this strategy, the principal shall serve as a leader and a learner (DuFour, and and Eaker, 2008).

In the learning community, the leaders have a future vision and run the learning process. They also seek learning through cooperating with others. The professional learning community is different from other communities. That is because the leaders and followers in this community provide much attention to the learning process. The members of this community seek developing their professional capabilities through carrying out joint decision making processes. The professional learning community aims at meeting the following goals (Abed Al-Mu'ti et al., 2018):

-Making reforms and achieving development in schools: The professional learning community aims at making reforms and developing the learning process schools. In this community, the learning process is developed through learning.

-Creating a school environment that motivates its members to learn: This is the most important goal that the professional learning community aims to achieve. The capability to establish this environment is affected by the capability to create a culture of cooperation that is based on friendship and support for each other. In this community, the members shall feel that they one family who work in harmony.

-Promoting a sense of collectivism: The learning community seeks promoting a sense of collectivism. It seek promoting collaboration when making decisions. It seeks promoting a common understanding for things. It seeks creating work teams that are based on cooperation. It promotes a sense of belonging within one to his/her work team. In this community, individuals realize that they can't work fully independently nor rely fully on others.

-Developing the skills and expertise of teachers and students: The professional learning community aims at developing the skills and expertise of teachers and students. It aims at developing the social, academic and professional expertise and personal skills of teachers and students. It aims at developing the critical and creative thinking skills of teachers and students. It aims at enabling students to conduct scientific research and collect data from scientific resources.

-Improving the academic achievement of students: The professional learning community aims at improving the academic achievement of students. In this community, the students show high academic achievement levels

In the professional learning community, the staff aim at improving the students' achievements. In this community, the leaders aim at passing standardized tests to students in order to track students' progress. The professional learning community provides much attention to group learning. Tawfiq (2017) sheds a light on the relationship between group learning and individual learning. He adds that the quality of education is affected by the school environment and the performance efficiency of the school staff. He adds that the school leaders must expand the knowledge of teachers. He adds that the school leaders must develop the skills of teachers. In the learning community, the skills and knowledge of teachers must be utilized in an organized and collective manner.

The extent of using conventional teaching methods has been decreasing. That is attributed to the use of technology in education which made the teachers become facilitators of knowledge. It is attributed to the emergence of modern teaching methods. Such methods include: active learning, cooperative learning, team work-based learning, and learning centred strategies.

The studies that have been published during the past forty years offer several modern learning methods. Through using modern learning methods, students shall be able to develop and expand their knowledge and teachers shall be able to 
provide students with convenient learning environment. Such an environment improve students' ability to comprehend information. It enables students to construct knowledge by themselves. Through using the modern learning methods, students must construct knowledge by themselves because learning serves as a process carried out by the student himself/herself. In fact, through using learning methods, students should be active learners who engage in the learning process.

Through using the modern learning methods, teachers shall strive to develop students' capabilities and talents. They are responsible for inspiring students and encouraging them to develop their capabilities, and talents and exert more effort. Through using the modern learning methods, students learn through cooperating with each other and the teachers to produce new knowledge together. Through using the modern learning methods, learning involves a social interaction. Fuller (2015) suggests that teachers are always in need for developing themselves professionally in order to improve the school performance (Fuller, 2015).

It's suggested that there are several requirements to be met before establishing the professional learning communities. Such requirements include the following ones:

-There must be a collaborative leadership that is supportive: In this community, the principals must allow each employee to practice leadership. They must collaborate with the staff in a democratic manner. They must delegate powers to them.

-There must be common visions and values: In this community, the employees must have common visions, and missions

-Collective creativity must be promoted: In this community, the employees shall cooperate with each other in order to product new knowledge and exchange it. Such cooperation shall positively affect the employees' practices in school.

-A supportive environment must be created: In this community, there must be a supportive environment that allows employees to engage in cooperative activities

In the light of the aforementioned information, the professional learning community aims to develop the capabilities of employees. It aims at allowing employees to practice leadership (Hord, 1997)

\section{Previous Studies}

This part presents the relevant empirical literature. There aren't many studies that shed a light on the role of VE teachers in the professional learning community. Hence, the researcher reviewed the studies that shed a light on the professional learning community in general. These studies are presented below. They are arranged based on the year of publication:

Mohammad (2019) aimed to explore the requirements of establishing a professional learning community in public schools. He aimed to explore the role of this community in improving the academic performance of public schools. He adopted a descriptive approach and used a survey. The sample consists from 784 primary, intermediate and secondary school teachers in Saudi Arabia. It includes female and male teachers. A questionnaire was used. It consists from 47 items. It was found that there is a statistically significant correlation between establishing a professional learning community in public schools and improving their academic performance. It was found that there isn't any statistically significant difference between the respondents' attitudes which can be attributed to school stage, academic qualification or experience.

Hussein et al. (2018) developed a vision for improving the performance of teachers in industrial secondary schools in Egypt through establishing professional learning communities. A descriptive approach was adopted. The questionnaire consists from 36 items. The sample consists from 1198 school principals, and heads of departments at the directorates of education in Egypt. It was found that extent of meeting the requirements of establishing professional learning communities in these schools is moderate.

Ibrahim and Al-Shahoomi (2018) aimed to explore the role of school principals in establishing professional learning communities in Omani schools. They adopted a descriptive approach and used a survey. They used a thirty-nine item questionnaire. The sample consists from 57 academic supervisors. It was found that the school principals play a very significant role in establishing professional learning communities in Omani schools. It was found that there isn't any statistically significant difference between the respondents' attitudes which can be attributed to gender, academic qualification or experience.

Tawfiq (2017) aimed to explore the role of teachers in establishing professional learning communities in Egyptian schools. He adopted a descriptive approach and used a survey. The sample consists from 147 female and male teachers who teach in various school stages. A sixty-six item questionnaire was used. It was found that the extent of establishing 
professional learning communities in Egyptian public schools is moderate. It was found that there isn't any statistically significant difference between the respondents' attitudes which can be attributed to major, educational stage or academic qualification.

Al-Mahmadain and Mousa (2017) aimed to explore the extent of meeting the requirements of establishing professional learning communities in the colleges affiliated with Al-Azhar University in Egypt. They adopted a descriptive approach and used a survey. They used a forty-one item questionnaire. The sample consists from 702 teachers. It was found that the extent of meeting the requirements of establishing professional learning communities in the colleges affiliated with Al-Azhar University in Egypt is moderate. It was found that there isn't any statistically significant difference between the respondents' attitudes which can be attributed to academic qualification or experience.

There are other relevant studies that are published in English language about professional learning communities. For instance, Bellibas et al. (2017) aimed to explore the role of teachers in Turkey in establishing professional learning communities. They adopted a descriptive approach and used a survey. They used a seventy-one item questionnaire. The sample consists from 492 female and male teachers and principals. Those principals and teachers and were selected from 27 schools. It was found that teachers in Turkey play a very significant role in establishing professional learning communities. It was found that employees in Turkish schools seek promoting a culture of collaboration, cooperation and group work.

Pang et al. (2016) aimed to explore the characteristics of professional learning communities in primary schools in Hong Kong. They adopted a descriptive approach and used a survey. They used a fifty-four item questionnaire. The sample consists from 345 female and male teachers. It was found that the extent of establishing professional learning communities in primary schools in Hong Kong is high. It was found that there isn't any statistically significant difference between the respondents' attitudes which can be attributed to gender or academic qualification.

Fuller (2015) aimed to explore the benefits of establishing professional learning communities in primary schools in the United States. He aimed to explore the role of these communities in improving the teaching practices of teachers. He adopted a descriptive approach and used a survey. He used a fifty-eight item questionnaire. It was found that there are numerous benefits derived from establishing professional learning communities in primary schools in the United States. It was found that there is significant positive correlation between establishing professional learning communities and the teaching practices of teachers.

Sompong et al. (2015) aimed to explore the extent of establishing professional learning communities in primary schools in Thailand. They adopted a descriptive approach and used a survey. To meet the study's goals, a forty-eight item questionnaire was used. The sample consists from 7458 female and male teachers. Those teachers were selected from 103 schools. It was found that the extent of establishing professional learning communities in primary schools in Thailand is moderate from the perspective of the primary school teachers. It was found that there isn't any statistically significant difference between the respondents' attitudes which can be attributed to gender, experience, or academic qualification.

\section{Comments on the Aforementioned Studies}

After reviewing the aforementioned studies, the researcher noticed the following things:

-Comments in terms of sample: The aforementioned studies differ from each other in terms of sample. For instance, Mohammad (2019), Tawfiq (2017), Al-Mahmadain and Mousa (2017) and Bellibas et al. (2017) sampled teachers. However, Ibrahim and Al-Shahoomi (2018) sampled academic supervisors. As for Hussein et al. (2018), they sampled school principals, and heads of departments at the directorates of education. Bellibas et al. (2017) sampled teachers and school principals. As for the researcher of the present study, he selected a sample consisting from several school principals and academic supervisors who were selected from the public schools that are under the supervision of Bani Obeid Directorate of Education in Irbid, Jordan.

-Comments in terms of approach: Similar to all the aforementioned studies, the researcher of the present study adopted a descriptive approach.

-Comments in terms of spatial limits: The aforementioned studies differ from each other in terms of the spatial limits. For instance, Mohammad (2019) conducted his study in Saudi Arabia and Hussein et al. (2018), Tawfiq (2017) and Al-Mahmadain and Mousa (2017) conducted his study in Egypt. Ibrahim and Al-Shahoomi (2018) conducted their study in Oman. Bellibas et al. (2018) conducted their study in Turkey. Pang et al. (2016) conducted their study in Hong Kong. Fuller (2015) conducted his study in the United States. Contrary to the aforementioned studies, the present study was conducted in the public schools that are under the supervision of Bani Obeid Directorate of Education in Irbid, Jordan. 
Contrary to the aforementioned studies, the present study targets the VE teachers working in public schools. It is considered a significant study because it sheds a light on a subject that is not addressed by any researcher. To be specific, it aims to explore the future role of vocational education teachers in the professional learning communities in in the public schools that are under the supervision of Bani Obeid Directorate of Education in Irbid, Jordan.

\section{Methodology}

This part offers a description for the study's sample and instrument. It presents information about the study's procedures and the reliability and validity of the study's instrument. It presents information about the data collections methods and statistical analysis methods.

\subsection{Approach}

The researcher adopted a descriptive approach. The descriptive approach is effective for exploring reality and identifying the factors that affect reality. It is adopted for describing, interpreting, and analysing reality. It is adopted to reach facts about the existent reality in order to improve it

\subsection{Sample}

The sample was selected through using the purposive sampling method. It consists from all the principals and academic supervisors who were working during the first semester of the academic year (2018/2019) in the public schools that are under the supervision of Bani Obeid Directorate of Education in Irbid, Jordan. To be specific, it consists from 91 principals and academic supervisors. Table (1) presents the distribution of the sample in accordance with their experience and academic qualification.

Table 1. The distribution of the sample in accordance with their experience and academic qualification.

\begin{tabular}{ccc}
\hline Variable & Academic qualification & Frequency \\
\hline Academic qualification & BA degree & 24 \\
& Postgraduate degree & 67 \\
Experience & Total & 91 \\
& Less than 5 years & 16 \\
& 5 -10 years & 40 \\
& More than 10 years & 35 \\
& Total & 91 \\
\hline
\end{tabular}

\subsection{The Study's Instrument}

The present study aims to explore future role of vocational education teachers in the professional learning communities in public schools from the perspective of principals and academic supervisors in Jordan. To meet the study's goals, the researcher developed an instrument that consists from two sections. The first section aims to collect data about the experience and academic qualification of the sample. The second sections aims to collect data about the respondents' attitudes

\subsection{Procedures for Developing the Instrument}

The following procedures were taken for developing the instrument:

a) The researcher reviewed the relevant studies that shed a light on the professional learning community. Reviewing the theoretical framework and questionnaires of several studies enabled the researcher to develop the questionnaire. To be specific, the researcher developed the instrument based on his own expertise and several studies. Such studies include: the ones conducted by Mohammad (2019), Hussein et al. (2018), Ibrahim and Al-Shahoomi (2018) and Tawfiq (2017). The initial version of the questionnaire consists from 37 items.

b) The initial version of the questionnaire was passed to several experts. Those experts include: experts in teaching and curricula, experts in educational administration and experts in psychology. They were asked to assess the initial version of the questionnaire in terms of language and relevancy

c) The researcher made changes to the initial version of the questionnaire based on the experts' opinions. For instance, some language mistakes were corrected. Some statements were merged with each other. Some statements were deleted. The researcher kept the statements that were approved by $85 \%$ of the experts. After that, the final version of the questionnaire was drafted. It consists from 25 items. 
d) The five point Likert scale was adopted. This scale consists from five rating categories; strongly agree, agree, moderate, disagree, and strongly disagree. These categories stand for the following scores respectively: 5, 4, 3, 2 and 1 . The researcher adopted statistical criteria to classify the means into high, moderate and low means. These criteria are shown below:

\section{(1-2.33: low)}

(2.34-3.67: moderate)

(3.68-5: high).

\subsection{Validity of the Instrument}

Face validity was measured through passing the initial version of the questionnaire to eight (8) experts. Those experts were asked to assess the questionnaire in terms of language, and relevancy. In the light of the experts' opinions, several changes were made to the questionnaire. For instance, some statements were redrafted. Some words were deleted. Some statements were deleted. The final version of the questionnaire consists from 25 items.

\subsection{Reliability of the Instrument}

To measure the reliability of the questionnaire, the test-re-test method was used. For instance, the researcher passed questionnaire forms to an exploratory sample. This exploratory sample consists from the 20 principals and academic supervisors. After two weeks, the questionnaire forms were passed again to this sample again. The Pearson correlation coefficient values were calculated. The overall Pearson correlation coefficient value is 0.90 . This value indicates that the questionnaire offers reliable results.

\subsection{Procedures of the Study}

The procedures listed below were taken to conduct this study:

-To conduct the present study, the researcher took the following procedures

-The researcher reviewed the relevant studies

-The researcher selected the sample. He measured the reliability and validity of the questionnaire

-The researcher obtained the required permissions. Such permission include the permission obtained from Bani Obeid Directorate of Education in Irbid, Jordan.

-The researcher distributed the questionnaire forms online to principals and academic supervisors. He asked the principals and academic supervisors to fill in the forms and send them online. The SPSS program was used for analyzing data.

\subsection{Variables}

a)-Independent variables: They are listed below:

-Academic qualification: It includes two categories; BA degree and postgraduate degree.

-Experience: It includes three categories; less than 5 years, 5-10 years, and more than 10 years.

b)-Dependent variable: It's represented in the future role of vocational education teachers in the professional learning communities in public schools from the perspective of principals and academic supervisors in Jordan

\subsection{Statistical Analysis}

In order to answer the first question, the researcher calculated means and standard deviations. To answer the second question, the researcher conducted the t-test and one way analysis of variance (ANOVA). To be specific, the t-test was conducted for exploring whether there is a significant difference between the respondents' attitudes that can be attributed to academic qualification. The one way analysis of variance (ANOVA) was conducted for exploring whether there is a significant difference between the respondents' attitudes that can be attributed to experience.

\section{Results and Discussion}

This part presents the study's results and discussion:

\subsection{Results and Discussion Related to the First Question}

Q.1. What is the future role of vocational education teachers in the professional learning communities in public schools from the perspective of principals and academic supervisors in Jordan in the schools that are under the supervision of Bani Obeid Directorate of Education in Irbid? 
To answer this question, means and standard deviations were calculated. Those means and standard deviations are presented in table (2) below:

Table 2. Means and standard deviations for identifying the respondents' attitudes towards the future role of vocational education teachers in the professional learning communities in public schools from the perspective of principals and academic supervisors in Jordan

\begin{tabular}{|c|c|c|c|c|c|}
\hline No. & Rank & Statement & Mean & Std. & Rank \\
\hline 25 & 1 & $\begin{array}{l}\text { VE teachers cooperate with their colleagues in setting } \\
\text { a common vision for developing their performance in } \\
\text { teaching students }\end{array}$ & 3.99 & 1.05 & High \\
\hline 20 & 2 & $\begin{array}{l}\text { VE teachers cooperate with their colleagues in setting } \\
\text { a common vision for improving the future } \\
\text { performance of the school }\end{array}$ & 3.95 & 1.09 & High \\
\hline 23 & 3 & $\begin{array}{l}\text { VE teachers contribute to setting effective solutions } \\
\text { for the problems facing the school }\end{array}$ & 3.91 & 1.09 & High \\
\hline 22 & 4 & $\begin{array}{l}\text { VE teachers engage in the decision making process } \\
\text { and ensure that the decisions are consistent with the } \\
\text { school vision }\end{array}$ & 3.90 & 1.05 & High \\
\hline 21 & 5 & $\begin{array}{l}\text { VE teachers seek establishing relationships that are } \\
\text { based on mutual trust and respect }\end{array}$ & 3.88 & 1.13 & High \\
\hline 24 & 6 & $\begin{array}{l}\text { VE teachers seek providing students with more } \\
\text { opportunities to advance and develop. }\end{array}$ & 3.84 & 1.07 & High \\
\hline 10 & 7 & $\begin{array}{l}\text { VE teachers seek providing suggestions for } \\
\text { improving the school performance }\end{array}$ & 3.82 & 1.08 & High \\
\hline 15 & 8 & $\begin{array}{l}\text { VE teachers seek attending meetings and } \\
\text { symposiums about the professional practices of } \\
\text { teachers. }\end{array}$ & 3.81 & 1.06 & High \\
\hline 11 & 9 & $\begin{array}{l}\text { VE teachers share information with their colleagues } \\
\text { about their successful experiences }\end{array}$ & 3.80 & 1.13 & High \\
\hline 19 & 10 & $\begin{array}{l}\text { VE teachers provide their colleagues with } \\
\text { information about their professional achievements. } \\
\text { They provide their colleagues with information about } \\
\text { their students' works in order to facilitate the learning } \\
\text { process }\end{array}$ & 3.79 & 1.22 & High \\
\hline 12 & 11 & $\begin{array}{l}\text { VE teachers exchange information with teachers in } \\
\text { other schools about their major }\end{array}$ & 3.78 & 1.13 & High \\
\hline 18 & 12 & $\begin{array}{l}\text { VE teachers exchange ideas and suggestions about } \\
\text { the way of improving students' achievement }\end{array}$ & 3.77 & 1.12 & High \\
\hline 13 & 13 & $\begin{array}{l}\text { VE teachers collaborate with their colleagues in } \\
\text { conducting scientific research. }\end{array}$ & 3.76 & 1.06 & High \\
\hline 17 & 14 & $\begin{array}{l}\text { VE teachers seek making the classroom environment } \\
\text { a convenient environment for exploration and } \\
\text { meditation }\end{array}$ & 3.75 & 1.13 & High \\
\hline 14 & 15 & $\begin{array}{l}\text { VE teachers employ the results of self-reflection to } \\
\text { improve the learning processes }\end{array}$ & 3.73 & 1.12 & High \\
\hline 16 & 16 & $\begin{array}{l}\text { VE teachers seek acquiring knowledge about global } \\
\text { experiences related to the development of the } \\
\text { teaching-learning process }\end{array}$ & 3.72 & 1.07 & High \\
\hline 2 & 17 & $\begin{array}{l}\text { VE teachers hold periodical sessions to assess the } \\
\text { content of the curriculum }\end{array}$ & 3.70 & 1.04 & High \\
\hline
\end{tabular}




\begin{tabular}{|c|c|c|c|c|c|}
\hline 1 & 18 & $\begin{array}{l}\text { VE teachers set common goals in collaboration with } \\
\text { their colleagues. They seek meeting these goals }\end{array}$ & 3.69 & 1.12 & High \\
\hline 5 & 19 & $\begin{array}{l}\text { VE teachers seek exchanging knowledge and } \\
\text { information in order to develop professional practices }\end{array}$ & 3.68 & 1.13 & High \\
\hline 4 & 20 & $\begin{array}{l}\text { VE teachers master the teaching methods that are } \\
\text { based on making projects and solving problems }\end{array}$ & 3.67 & 1.06 & $\begin{array}{c}\text { Moderat } \\
\mathrm{e}\end{array}$ \\
\hline 3 & 21 & $\begin{array}{l}\text { VE teachers engage in the process of making creative } \\
\text { initiatives that enable the school to excel }\end{array}$ & 3.66 & 1.13 & $\begin{array}{c}\text { Moderat } \\
\mathrm{e}\end{array}$ \\
\hline 8 & 22 & $\begin{array}{l}\text { VE teachers employ a variety of learning activities } \\
\text { inside and outside the classroom }\end{array}$ & 3.64 & 1.12 & $\begin{array}{c}\text { Moderat } \\
\mathrm{e}\end{array}$ \\
\hline 7 & 23 & $\begin{array}{l}\text { VE teachers identify the learners who are in need for } \\
\text { more attention }\end{array}$ & 3.62 & 1.07 & $\begin{array}{c}\text { Moderat } \\
\mathrm{e}\end{array}$ \\
\hline 9 & 24 & $\begin{array}{l}\text { VE teachers encourage learners to develop their } \\
\text { critical and creative thinking }\end{array}$ & 3.60 & 1.04 & $\begin{array}{c}\text { Moderat } \\
\mathrm{e}\end{array}$ \\
\hline \multirow[t]{2}{*}{6} & 25 & $\begin{array}{l}\text { VE teachers provide learners with opportunities to } \\
\text { implement and exchange knowledge }\end{array}$ & 3.59 & 1.12 & $\begin{array}{c}\text { Moderat } \\
\mathrm{e}\end{array}$ \\
\hline & & Overall & 3.79 & 1.08 & High \\
\hline
\end{tabular}

Based on table (2), the respondents' attitudes are positive towards the future role of vocational education teachers in the professional learning communities in public schools. That is concluded because the overall mean is 3.79 . Ninteen statements show high means. Six items show moderate means.

The mean of statement (25) is 3.99. It is ranked first. The latter statement states the following: (VE teachers cooperate with their colleagues in setting a common vision for developing their performance in teaching students). The mean of statement (20) is 3.95. It's ranked second. The latter statement states the following: (VE teachers cooperate with their colleagues in setting a common vision for improving the future performance of the school).

The mean of statement (23) is 3.91. It's ranked third. The latter statement states the following: (VE teachers contribute to setting effective solutions for the problems facing the school). The mean of statement (6) is 3.59. It's ranked last. The latter statement states the following: (VE teachers provide learners with opportunities to implement and exchange knowledge).

The positive attitudes towards the role of VE teachers may be attributed to the fact that the Jordanian Ministry of Education developed high standards for assessing the performance of VE teachers in public schools. They may be attributed to having supportive leaders who provide much attention to teachers and seek solving teachers' problems. Having such leaders shall contribute to the development of public schools. The positive attitudes towards the role of VE teachers may be attributed to the engagement of VE teachers in public schools in the decision making process. Such engagement shall motivate those teachers to improve their performance in teaching.

The positive attitudes towards the role of VE teachers may be attributed to the fact that VE teachers in public schools are keen on developing themselves professionally and sharing expertise with each other. Those teachers share expertise with each other through visits. The positive attitudes towards the role of VE teachers may be attributed to the beliefs of those teachers. For instance, those teachers believe that establishing professional learning communities requires having work teams who seek meeting the school goals and improving and reforming schools. They also believe that establishing such communities requires having supportive environment that is dominated by trust, harmony, and commitment. They believe that establishing such communities requires having staff who handle responsibility.

The latter results are consistent with the results concluded by Ibrahim and Al-Shahoomi (2018). The latter researchers found that school principals play a very significant role in establishing professional learning communities in Omani schools. The latter results are consistent with the results concluded by Bellibas et al. (2017). The latter researchers found that teachers in Turkey play a very significant role in establishing professional learning communities. The latter results are consistent with the results concluded by Pang et al. (2016). The latter researchers found that the extent of establishing professional learning communities in primary school in Hong Kong is high. The latter results are inconsistent with the results concluded by Hussein et al. (2018). The latter researchers found that the extent of meeting the requirements of establishing professional learning communities in these schools is moderate. 
The latter results are inconsistent with the results concluded by Tawfiq (2017). The latter researcher found that the extent of establishing professional learning communities in Egyptian public schools is moderate. The latter results are inconsistent with the results concluded Al-Mahmadain and Mousa (2017). The latter researchers found that the extent of meeting the requirements of establishing professional learning communities in the colleges affiliated with Al-Azhar University in Egypt is moderate

\subsection{Results and Discussion Related to the Second Question}

Q.2. Is there any statistically significant differences between the respondents' attitudes which can be attributed to academic qualification or experience?

- Results and discussion related to academic qualification:

In order to identify whether there is any statistically significant differences between the respondents' attitudes which can be attributed to academic qualification, the t-test was conducted. The results of the latter test are presented in table (3) below:

Table 3. The results of the t-test for identifying whether there is any statistically significant differences between the respondents' attitudes which can be attributed to academic qualification

\begin{tabular}{|c|c|c|c|}
\hline $\begin{array}{l}\text { Academic } \\
\text { qualification }\end{array}$ & Mean & & $\begin{array}{l}\text { The calculated Sig. } \\
\text { t-value }\end{array}$ \\
\hline BA degree & 100.42 & 12.47 & -1.57 \\
\hline $\begin{array}{l}\text { Postgraduate } \\
\text { degree }\end{array}$ & 103.18 & 12.28 & \\
\hline
\end{tabular}

Based on table (3), it was found that there isn't any statistically significant difference between the respondents' attitudes which can be attributed to academic qualification. That is because the t-value is -1.57 . The latter value isn't statistically significant. The latter result may be attributed to the fact that principals and academic supervisors of various qualifications realize the significant role of vocational education teachers in the professional learning communities in public schools. It may be attributed to the fact that all principals and academic supervisors realize that several requirements must be met for establishing professional learning communities in schools. It may be attributed to the fact that all principals and academic supervisors realize the significant role of professional learning communities in improving the performance of teachers and developing them professionally.

The latter result is consistent with the result concluded by Mohammad (2019), brahim and Al-Shahoomi (2018), Tawfiq (2017), Al-Mahmadain and Mousa (2017), Pang et al. (2016) and Sompong et al. (2015).

-Results and discussion related to experience

To identify whether there is any statistically significant differences between the respondents' attitudes which can be attributed to experience, one way analysis of variance (ANOVA) was conducted. The results of the latter analysis are presented in table (4) below.

Table 4. The results of one way analysis of variance (ANOVA) for identifying whether there is any statistically significant differences between the respondents' attitudes which can be attributed to experience

\begin{tabular}{lrrrrrrrr}
\hline $\begin{array}{l}\text { Source } \\
\text { variance }\end{array}$ & $\begin{array}{l}\text { Sum } \\
\text { squares }\end{array}$ & of & Df. & & $\begin{array}{l}\text { Mean } \\
\text { squares }\end{array}$ & of & F value & Sig. \\
\hline $\begin{array}{l}\text { Between } \\
\text { groups }\end{array}$ & 0.62 & 2 & 0.31 & 1.32 & 0.26 \\
within groups & 123.47 & 88 & 1.4030 & & \\
\hline
\end{tabular}

Based on table (4), it was found that there isn't any statistically significant difference between the respondents' attitudes which can be attributed to experience. That is because the calculated $f$ value is 1.32 . The latter value isn't statistically significant. The latter result indicates that experience doesn't affect the attitude of principals and academic supervisors aren't affected by their experience. The latter result indicates that principals and academic supervisors of various experiences believe that VE teachers play a significant role in the professional learning communities. It may be attributed to the belief of principals and academic supervisors of various experiences that professional learning communities play a significant role in improving teachers professionally and providing them with expertise. 
The latter result is consistent with the result concluded by Mohammad (2019), Ibrahim and Al-Shahoomi (2018), Al-Mahmadain and Mousa (2017), and Sompong et al. (2015).

\section{Conclusion}

It was found that principals and academic supervisors have positive attitudes towards the future role of vocational education teachers in the professional learning communities in public schools. It was found that VE teachers play a significant role in establishing professional learning communities in public schools. It was found that there isn't any significant difference between the respondents' attitudes which can be attributed to their experience or academic qualification.

\section{Recommendations}

In the light of the aforementioned results, the researcher recommends the following:

1) Creating vocational training departments in public schools. Such departments must provide support for the professional learning communities

2) Promoting a culture of cooperation in schools. That can be done through launching group projects

3) Holding training courses and workshops for VE teachers in public schools. Such training courses and workshop must promote awareness about the significance of professional learning communities. They must promote awareness about the expected future role of VE teachers.

4) Providing teachers with knowledge about models of professional learning communities and their role in promoting a culture of ongoing learning

5) Providing more attention to the statements that show moderate means. For instance, efforts must be exerted to make sure that VE teachers master the teaching methods that are based on making projects and solving problems. In addition, efforts must be exerted to make sure that VE teachers engage in the process of making creative initiatives that enable the school to excel. More efforts must be exerted to make sure that VE teachers employ a variety of learning activities inside and outside the classroom. More efforts must be exerted to make sure that VE teachers encourage learners to develop their critical and creative thinking. More efforts must be exerted to make sure that VE teachers provide learners with opportunities to implement and exchange knowledge.

6) Conducting more studies about professional learning communities in private schools. Such studies must target variables that aren't targeted in this study

\section{Acknowledgements}

The researcher would like to thank the Jordanian Ministry of Education for exerting much effort to improve the quality of school education.

\section{References}

Abed Al-Mu'ti, Yousif (2012). The transformational leadership style as an approach to improve the performance of school principals in Egypt. Education- The Egyptian Association for Comparative Education and Educational, 5(7), 147-171.

Abu Al-Nour, Mahmoud (2010). Compliance with the standards of excellent administration at the primary schools in Egypt. A research submitted to a conference titled (Accreditation and quality assurance at educational institutions). This conference is the thirteenth conference of (The Egyptian Association for Comparative Education and Educational Administration). It is held in collaboration with the Faculty of Education in Beni Suef University at Cairo University (Cairo: Dar Al-Feker Arabi).

Al-Hussaini, Azzah and Al-Zghool, Eman (2009). Organizational trust and the performance effectiveness of schools in the Arab Republic of Egypt. The Egyptian Association for Comparative Education and Educational Administration, 8(17), 21-95.

Al-Mahmadain, Heshmat and Mousa, Ahmad (2017). The requirements of establishing professional learning communities in the colleges affiliated with Al-Azhar University from the teachers' perspective. The Journal of the Faculty of Education -Al-Azhar University-Egypt, 17(2), 12-72. Retrieved from: http://search.shamaa.org/FullRecord?ID=250565

Al-Nabawi, Ameen (2007). Learning communities as an approach to academic accreditation in schools: A comparative study in the United States of America, Japan, Hong Kong and Korea and the possibilities of benefiting from them in Egypt. The Journal of Education and development, 1(4), 106-148. ISSN: 1112-8070 
Al-Sagh'eer, Ahmad (2009). Learning communities as a quality assurance approach: A field study in the Emirati society. The Journal of the Faculty of Education, 4(2), 47-73. Retrieved from: http://staffsites.sohag-univ.edu.eg/stuff/posts/show/6664?p=posts

Al-Salem (2005). Learning organizations. First edition. Cairo, Egypt: The Arab Organization of Administrative Development

Atteyeh, Redah (2010). The role of the primary school administration in Egypt: Development and rigidity: A field study. Cairo: Egypt. The National Center of Research and Development.

Hasanain, Ahmad (2008). The school culture in the 21st century: A field study in public schools. The Journal of Education and development, 11(27), 36-71.

Haidar, Abed Al-Lateef and Al-Mosailihi, Mohammad (2006). The role of school as a professional learning community in promoting and developing a culture of learning. The Journal of the Faculty of Education, 21(23), $39-66$.

Hussein, Ahmad; Mursi, Omar and Al-Qusairi, Abduh (2018). Developing the performance of teachers in industrial secondary schools in Egypt through establishing professional learning communities in accordance with the experiences of some countries: A field study. The Journal of Culture and Development, 18(128), 1-34.

Ibrahim, Hussam Al-Deen and Al-Shahoomi, Saeed (2018). The role of school principals in establishing professional learning communities in Oman from the perspective of academic supervisors. The Journal of the Faculty of Education in Benha University, 29(116), 335-369.

Melton, Cox (2010). Introduction to faculty learning communities. First edition. Saudi Arabia. Al-Abeekan Bookshop.

Mohammad, Ghada (2009). Organizational support for teachers and the innovative environment at public secondary schools: An analytical study: Unpublished MA thesis. Ain Shams University. Egypt.

Mohammad, Maher (2019). Establishing professional learning communities as a way for improving academic performance in public schools in the Kingdom of Saudi Arabia. The Journal of the Islamic University-Gaza, 27(6), 63-92. Retrieved from: https://journals.iugaza.edu.ps/index.php/IUGJEPS/article/view/6206

Richard, Dover and Robert, Eker (2008). Professional learning communities in the workplace. Translated by: Dhahran Ahliyya Schools. The second edition. Al-Damam. Kingdom of Saudi Arabia. Dar Al-Ketab Al-Tarbawi.

Sulaiman, Eman (2009). Organizational conflict and leadership patterns among public secondary school principals in the Arab Republic of Egypt. Unpublished MA thesis. Ain Shams University. Egypt.

Tawfiq, Feefi (2017). A future scenario for improving the role of professional learning communities in public schools in Sohaj. The Educational Journal, 7(4), 111-114.

Bellibas, M., Bulut, O. \& Gedik, S.(2017). Investigating Professional Learning Communities in Turkish Schools: The Effects of Contextual Factors. Professional Development in Education, 3(43), 374-399. https://doi.org/10.1080/19415257.2016.1182937

Christopher, B. (2008). Towards a Learning Community: The Journey of a Maltese Catholic Church School, Management in Education, 22(3), 22-61. https://doi.org/10.1177/0892020608093261

Earley, P.; and Weindling, D. (2004). Understanding School Leadership. The first edition, the United States: SAGE Publications Ltd. http://doi.org/10.4135/9781446215678

Fuller, S. (2014). The Impact of Professional Learning Communities on Teachers and Students in an Elementary School, Published PhD dissertation, Texas A \& M University. Texas. The United States.

Hord, M. (1997). Professional Learning Communities of Continuous Inquiry and Improvement, Texas, USA, South West Educational Development Laboratory.

Moilanen, R. (2011) Diagnostic tools for learning organizations, The Learning Organization, 8(1), 6-20. https://doi.org/10.1108/09696470110366507

Morrissey. M (2014). Professional learning communities: An ongoing exploration, $1^{\text {st }}$ edition, Texas, the United States, Southwest Educational Development Laboratory 
Pang, N., Wang, T. \& Leung, Z. (2016). Educational reforms and the practices of professional learning community in Hong Kong primary schools, Asia Pacific Journal of Education, 36(2), 231-247. https://doi.org/10.1080/02188791.2016.1148852

Raymond, W. (2016). Leadership for School Reform: Do Principal Decision Making Styles Reflect a Collaborative Approach, Canadian Journal of Educational Administration and Policy, (53), 1-22.

Sompong, S., Erawan, P. \& Dharm, S. (2015). The development of professional learning community in primary schools. Educational Research and Reviews, 10(21), 2789-2796, https://doi.org/10.5897/ERR2015.2343

Wong, J. (2010). What makes a professional learning community possible? A case study of a Mathematics department in a junior secondary school in China, Asia Pacific Educ, 1(2), 131-139. https://doi.org/10.1007/s12564-010-9080-6 